\title{
ANALISIS TABARRU DAN KLAIM PESERTA PADA ASURANSI SYARIAH DI INDONESIA Wiwik Saidatur Rolianah ${ }^{1}$ \\ Sekolah Tinggi Ekonomi Islam Kanjeng Sepuh Sidayu Gresik wiwik@steikassi.ac.id
}

\begin{abstract}
Abstrak
Asuransi syariah yang muncul dari tahun 1994 yang didukung banyak pihak telah mewarnai dunia lembaga keuangan syariah. Perbedaan asuransi syariah dan konvensional pada dasarnya terletak pada preminya, yaitu pada asuransi syariah terdapat dua bagian meliputi unsur tabungan dan unsur tabarru. Penelitian yang berjudul "Analisis Tabarru dalam Asuransi Syariah di Indonesia terhadap Klaim Peserta” ini adalah hasil dari penelitian yang bertujuan menganalisis antara unsur tabarru dan klaim peserta pada asuransi syariah di Indonesia. Dari hasil penelitian yang dilakukan peneliti menemukan keterkaitan antara unsur tabarru dan jumlah klaim asuransi yang diberikan kepada peserta asuransi syariah. Namun, untuk dana tabarru tidak ditentukan berdasarkan jumlah premi yang dibayarkan, kecuali untuk dana tabungan maka dan bagi hasil peserta asuransi syariah.
\end{abstract}

Kata Kunci: Asuransi Syariah, Tabarru, Klaim Asuransi, Lembaga Keuangan Syariah.

\begin{abstract}
Sharia insurance that emerged from 1994 have enliven the development of sharia financial institution. The difference between sharia insurance and conventional insurance basically lies in the premium, namely in Islamic insurance there are two parts covering the savings and the tabarru element. The study, entitled "Analysis of Tabarru in Sharia Insurance in Indonesia against Participants' Claims" is the result of a study aimed at analyzing between the elements of Tabarru and participant claims on sharia insurance in Indonesia. From the results of research conducted by researchers found a link between the elements of tabarru and the number of insurance claims given to participants of sharia insurance. However, for Tabarru funds are not determined based on the amount of premium paid, except for savings funds and the profit sharing of sharia insurance participants.
\end{abstract}

Keywords: Sharia Insurance, Tabarru, Insurance claim, Sharia Financial Institutions. 


\section{PENDAHULUAN}

Di Indonesia, asuransi syariah yang sudah mulai berdiri sejak tahun 1994 yaitu PT Syarikat Takaful Indonesia (STI) yang dimotori oleh Ikatan Cendekiawan Muslim Indonesia (ICMI) melalui Yayasan Abdi Bangsa, Bank Muamalat Indonesia, PT Asuransi Jiwa Tugu Mandiri, Departemen Keuangan RI, serta beberapa pengusaha Muslim Indonesia (Sawitri, 2011). Di mana asuransi syariah mewarnai dunia lembaga keuangan syariah, namun untuk keberadaanya mulai tren ditahun 2010 yang ditandai dengan banyaknya pemilik modal yang berani melakukan investasi di bidang ini .

Pembeda asuransi syariah dan konvensional pada dasarnya terletak pada preminya, yaitu pada asuransi syariah terdapat dua bagian meliputi unsur tabungan dan unsur tabarru. Dana yang berasal dari dua bagian ini tidak bisa dipakai untuk biaya komisi agen sehingga dana peserta tetap utuh dan seandainya peserta mengundurkan diri, uang premi akan dikembalikan sepenuhnya, kecuali dana tabarru. Sedangkan asuransi konvensional, premi yang diperoleh perusahaan bisa dipakai untuk biaya/loading dalam bentuk pembayaran komisi agen, biaya administrasi, biaya reasuransi, biaya cetak polis, dan lain sebagainya sehingga jika peserta mengundurkan diri maka tidak memiliki nilai tunai pada tahun pertama ikut asuransi (Amrin, 2006).

Pada asuransi syariah disebutkan bahwasanya klaim yang didapat pada asuransi syariah, jika premi yang dibayarkan kecil maka klaim yang diterima akan kecil juga dan sebaliknya jika premi yang dibayarkan besar maka klaim yang diterima akan besar juga (Sulistyowati, 2012). Melihat hal ini, seolah-olah konsep ta'awun yang diusung oleh asuransi syariah tidak terlihat karena pertolongannya berdasarkan apa yang diperoleh terlebih dahulu maka yang akan didapatkan. Sedangkan dalam ajaran Islam sendiri mengajarkan umatnya untuk menolong saudaranya tanpa melihat kedudukan.

Dilihat pada prinsip asuransi syariah yaitu tolong menolong (ta'awun), prinsip yang paling utama dalam konsep asuransi syariah ini terdapat dalam Al Quran. Hal ini mengandung arti bahwa setiap peserta asuransi ketika melangsungkan akad harus memiliki niat untuk tolong menolong di antara atau sesama peserta lainnya. Dan saling tolong atau saling tanggung dalam hal ini sangat dianjurkan dalam Islam (Arif, 2012).

Masyarakat sendiri sangatlah berharap kepada lembaga-lembaga bisnis syariah untuk lebih mengutamakan ta'awun dari pada unsur keuntungan semata. Kenyataan yang sering 
dijumpai oleh konsumen hampir tidak kelihatan seperti apa yang didambakan oleh konsumen (Saharuddin, 2014).

\section{KAJIAN TEORI}

\section{Konsep Dasar Asuransi Syariah}

Asuransi syariah adalah suatu pengaturan pengelolaan risiko untuk memenuhi ketentuan syariah, tolong menolong secara mutual yang melibatkan peserta dan operator (Iqbal, 2006). Sedangkan menurut Fachrudin, asuransi adalah suatu usaha saling melindungi dan tolong menolong diantara sejumlah orang melalui investasi dalam bentuk aset atau tabarru' melalui akad sesuai dengan syariah (Nawawi, 2009).

Dewan Sariah Nasional Majelis Ulama Indonesia (DSN-MUI) dalam fatwanya tentang pedoman umum asuransi syariah, memberikan definisi tentang asuransi. Menurutnya, asuransi syariah merupakan usaha saling melindungi dan tolong menolong antara peserta dengan investasi dalam bentuk asset dan dana tabarru yang memberikan pengembalian untuk menghadapi risiko melalui akad yang sesuai dengan syariah.

Dari definisi tersebut tampak bahwa asuransi syariah bersifat saling melindungi dan tolong menolong yang sering disebut ta'awun yang merupakan prinsip hidup saling melindungi dan saling menolong atas dasar ukhuwah islamiyah antara anggota asuransi dalam menghadapi risiko yang ada. Karena itu, premi pada asuransi syariah adalah sejumlah dana yang dibayarkan oleh peserta yang terdiri dari dana tabungan dan dana tabarru. Dana tabungan adalah dana titipan dari peserta asuransi syariah dan akan mendapatkan bagi hasil dari pendapatan investasi bersih yang diperoleh setiap tahun. Dana tabungan dan bagi hasil akan dikembalikan kepeserta apabila perserta yang bersangkutan mengajukan klaim. Sedangkan dana tabarru adalah derma atau dana kebajikan yang diberikan dan diikhlaskan oleh peserta asuransi jika sewaktu-waktu dipergunakan untuk membayar klaim untuk peserta yang tertimpa musibah (Sula, 2004). Asuransi syariah memiliki beberapa ciri utama, yaitu (S.Pradja, 2012):

1. Akad asuransi syariah bersifat tabarru', sumbangan yang diberikan ke pihak asuransi tidak boleh ditarik kembali. Jika bukan tabarru' maka akan dibayarkan berupa tabungan yang diterima.

2. Akad asuransi bukan akad mulzim (perjanjian yang wajib dilaksanakan) bagi kedua belah pihak. Ini karena pihak anggota ketika memberikan sumbangan tidak mengharapkan adanya imbalan, dan apabila terdapat imbalan maka itu didapat melalui izin jamaah. 
3. Dalam asuransi syariah tidak ada pihak yang lebih kuat atau lebih lemah karena keputusan dan aturan diambil berdasarkan keputusan jamaah.

4. Akad asuransi syariah bersih dari maysir, gharar, dan riba.

5. Asuransi syariah bernuansa kekeluargaan yang kental.

Adanya Asuransi Takaful Umum pada tahun 1994 ini, menandai adanya asuransi syariah yang ada di Indonesia. Asuransi syariah ini memiliki dua jenis asuransi, yaitu asuransi jiwa syariah dan asuransi umum syariah. Dalam pengelolaannya, perusahaan asuransi syariah bertindak sebagai pengelola yang amanah dan cerdas agar menguntungkan semua pihak. Dan untuk dana peserta asuransi dikelola dengan hati-hati dan cermat supaya bisa memenuhi kebutuhan asuransi sesama peserta yang mengalami musibah dan hasil investasi yang optimal (Salamudin, 2014).

Tabel 1

Asuransi Syariah di Indonesia Desember 2016

\begin{tabular}{|l|c|c|}
\hline \multicolumn{1}{|c|}{ Keterangan } & $\begin{array}{c}\text { Jumlah Industri Syariah } \\
\text { (Unit) } \\
\text { Number of Sharia } \\
\text { Industries (Units) }\end{array}$ & $\begin{array}{c}\text { Jumlah Perusahaan } \\
\text { Unit Usaha Syariah } \\
\text { (Unit) } \\
\text { Number of Sharia } \\
\text { Business Units } \\
\text { (Units) }\end{array}$ \\
\cline { 2 - 3 } 1. Asuransi Syariah & 11 & 47 \\
a. Asuransi Jiwa Syariah & 6 & 21 \\
b. Asuransi Umum Syariah & 4 & 24 \\
c. Reasuransi Syariah & 1 & 2 \\
2. Lembaga Pembiayaan Syariah & 7 & 42 \\
a. Perusahaan Pembiayaan Syariah & 3 & 38 \\
b. Perusahaan Modal Ventura Syariah & 4 & 3 \\
c. Perusahaan Pembiayaan Infrastruktur Syariah & - & 1 \\
3. Lembaga Jasa Keuangan Khusus Syariah & 2 & 4 \\
4. Lembaga Keuangan Mikro Syariah & 13 & - \\
\hline \multicolumn{2}{|c|}{ JUMLAH } & $\mathbf{9 4}$ \\
\hline \multicolumn{2}{|c|}{} \\
\hline \multicolumn{2}{|c|}{} \\
\hline
\end{tabular}

\section{Landasan Asuransi Syariah}

Landasan dari asuransi syariah adalah sumber dari pengambilan hukum praktik asuransi syariah.

a. Al-Qur'an

1) Asuransi syariah yang berdasarkan konsep tolong menolong dalam kebaikan dan takwa yang sesuai dengan Al Quran surah al-Maidah (5) ayat 2 (Latifah, 2012):

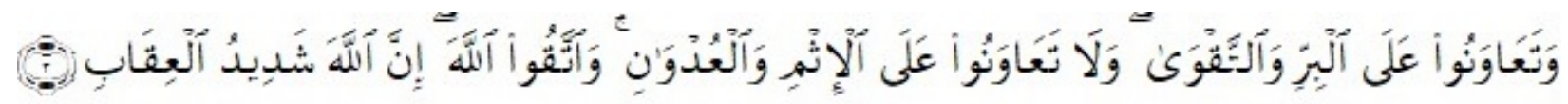

"Dan tolong-menolonglah kamu dalam (mengerjakan) kebajikan dan takwa, dan jangan 
tolong-menolong dalam berbuat dosa dan pelanggaran. dan bertakwalah kamu kepada Allah, Sesungguhnya Allah Amat berat siksa-Nya."

2) Al Quran surat al-Baqarah (2) ayat 185:

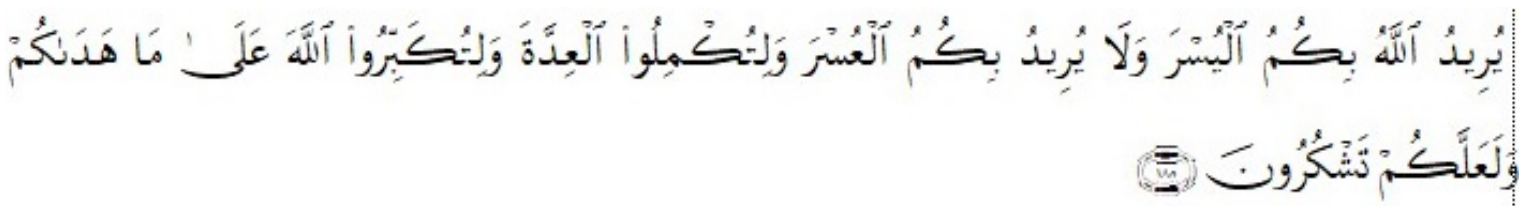

"Allah menghendaki kemudahan bagimu, dan tidak menghendaki kesukaran bagimu. Dan hendaklah kamu mencukupkan bilangannya dan hendaklah kamu mengagungkan Allah atas petunjuk-Nya yang diberikan kepadamu, supaya kamu bersyukur."

3) Al Quran surat al-Baqarah (2) ayat 261:

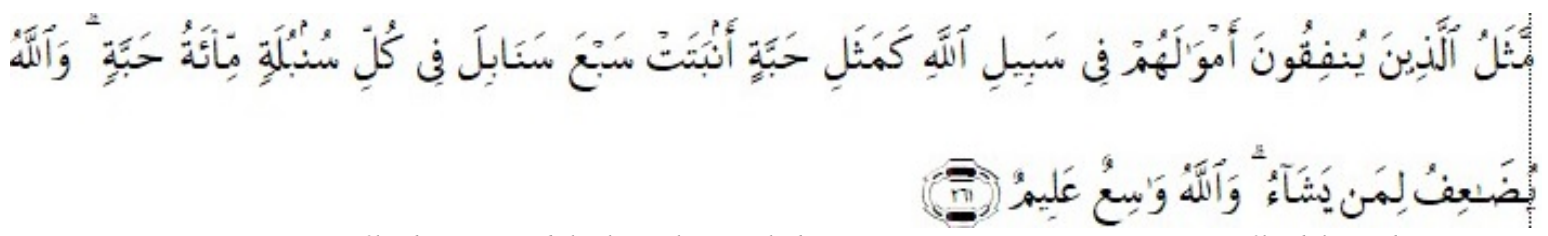

"Perumpamaan (nafkah yang dikeluarkan oleh) orang-orang yang menafkahkan hartanya di jalan Allah adalah serupa dengan sebutir benih yang menumbuhkan tujuh bulir, pada tiap-tiap bulir seratus biji. Allah melipat gandakan (ganjaran) bagi siapa yang Dia kehendaki. dan Allah Maha Luas (karunia-Nya) lagi Maha mengetahui."

4) Al Quran surat Yusuf (12) ayat 46-49:

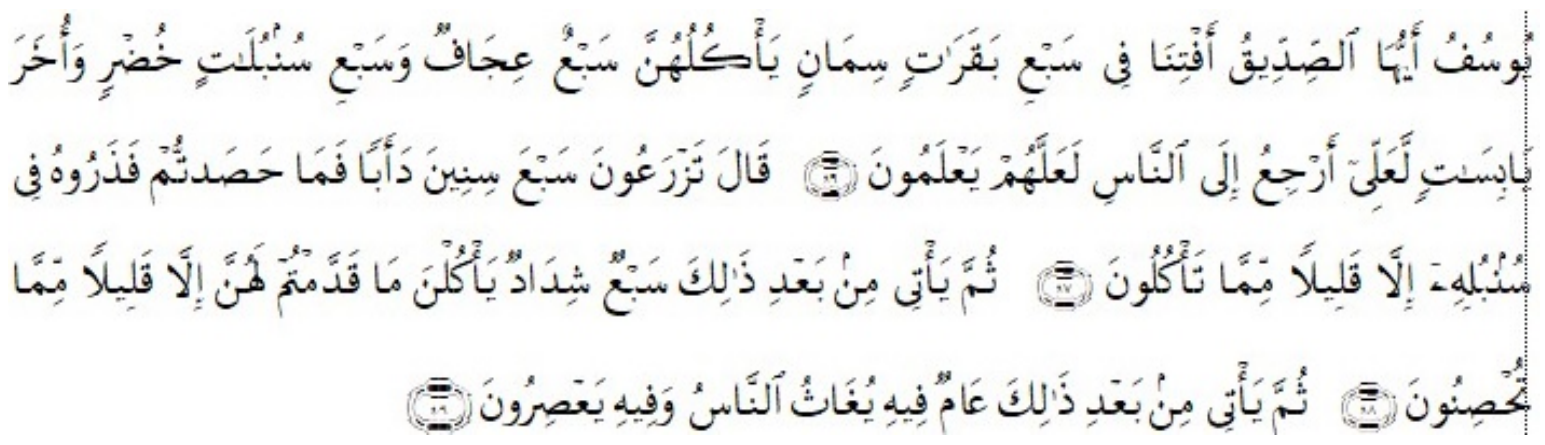

“(setelah pelayan itu berjumpa dengan Yusuf Dia berseru): "Yusuf, Hai orang yang Amat dipercaya, Terangkanlah kepada Kami tentang tujuh ekor sapi betina yang gemuk-gemuk yang dimakan oleh tujuh ekor sapi betina yang kurus-kurus dan tujuh bulir (gandum) yang hijau dan (tujuh) lainnya yang kering agar aku kembali kepada orang-orang itu, agar mereka mengetahuinya. Yusuf berkata: Supaya kamu bertanam tujuh tahun (lamanya) sebagaimana biasa; Maka apa yang kamu tuai hendaklah kamu biarkan dibulirnya kecuali sedikit untuk kamu makan. Kkemudian sesudah itu akan datang tujuh tahun yang Amat sulit, yang menghabiskan apa yang kamu simpan untuk menghadapinya (tahun sulit), kecuali sedikit dari (bibit gandum) yang kamu simpan. Kemudian setelah itu akan datang tahun yang padanya manusia diberi hujan (dengan cukup) dan dimasa itu mereka memeras anggur." 
b. Sunnah/Hadits Nabi

1) Tentang menghilangkan kesulitan seseorang

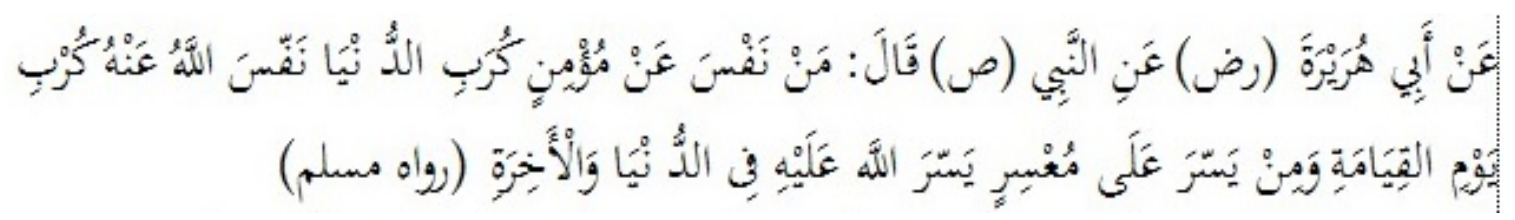

"Diriwayatkan oleh Abu Hurairah ra, Nabi Muhammad bersabda: Barangsiapa yang menghilangkan kesulitan duniawinya seorang mukmin, maka Allah SWT akan menghilangkan kesulitannya pada hari kiamat. Barangsiapa yang mempermudah kesulitan seseorang, maka Allah SWT akan mempermudah urusannya di dunia dan di akhirat. (HR. Muslim)".

2) Tentang niat

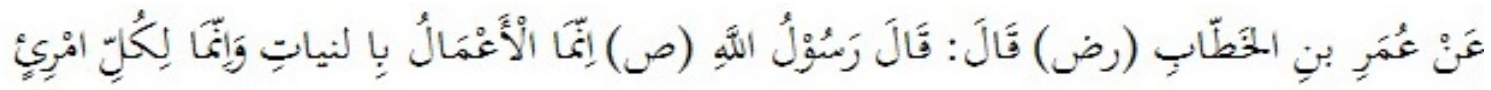

$$
\begin{aligned}
& \text { مَانَوكي (متَفق عليه) }
\end{aligned}
$$

"Diriwayatkan oleh Umar bin Khattab ra, dia berkata: Telah bersabda Rasulullah SAW: Sesungguhnya semua pekerjaan itu (tergantung) dengan niatnya, dan setiap orang itu (tergantung) dari apa yang diniatkannya. (Muttafaq alaih)”

3) Tentang perjanjian

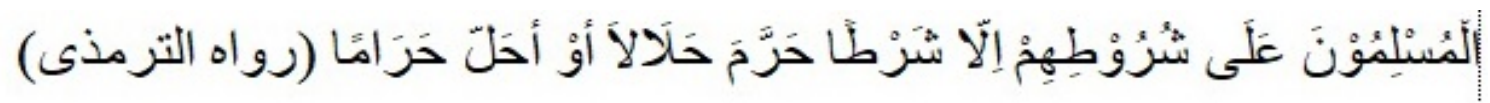

"Orang-orang muslim itu terikat dengan syarat yang mereka sepakati, kecuali syarat yang mengharamkan yang halal atau menghalalkan yang haram. (HR. At-Turmudzi)”

4) Tentang menghindari risiko

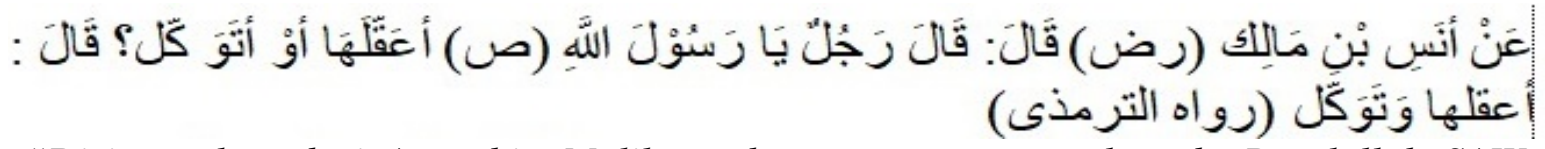

“Diriwayatkan dari Anas bin Malik ra, bertanya seseorang kepada Rasulullah SAW, tentang (untanya): Apa (unta) ini saya ikat saja atau langsung saya bertawakal pada (Allah SWT.)? Bersabda Rasulullah SAW.: Pertama ikatlah unta itu kemudian bertakwalah kepada Allah SWT. (HR. At-Turmudzi).”

\section{Implementasi Akuntansi Asuransi Syariah}

Penetapan bentuk akad akan berdampak pada sistem akuntansi yang akan diterapkan, dan akad dalam asuransi terdapat dua hal yaitu (Amirun, 2019):

a. Akad Mudharabah

Mudarabah berasal dari kata dharb, berarti memukul atau berjalan. Pengertian memukul atau berjalan ini lebih tepatnya adalah proses seseorang memukulkan kakinya dalam 
menjalankan usaha. Secara teknis Al Mudarabah adalah akad kerja sama usaha antara dua pihak di mana pihak pertama (sahibul mal) menyediakan seluruh (100\%) modal, sedangkan pihak lainya menjadi pengelola. Keuntungan usaha secara Mudarabah di bagi menurut kesepakatan yang di tuangkan dalam kontrak, sedangkan apabila rugi di tanggung oleh pemilik modal selama kerugian itu bukan akibat kelalaian Si pengelola (Kartiko, 2019).

Dalam akad mudharabah terdapat pemisahan dana antara dana peserta asuransi dan pemegang saham, yang mana perusahaan bertindak sebagai pengelolah dana yang diperoleh dari peserta dipakai apabila peserta mengalami musibah. Di sisi lain, peserta menyetujui bahwa dana yang disetorkan akan dikelola secara profesional dan di akhir periode bagi peserta yang tidak mengalami adanya klaim maka akan mendapatkan bagi hasil. Oleh karena itu, sistem akuntansi yang diterapkan harus memisahkan antara akuntansi dana pemegang saham dengan dana akuntansi peserta asuransi.

Contoh akad mudharabah:

1) Keuntungan penanggung dari hasil pengelolaan premi tabarru pada akhir pertanggungan akan dibagikan proporsional kepada seluruh tertanggung berdasarkan prinsip bagi hasil dengan nisbah 70\% untuk penanggung dan 30\% untuk seluruh tertanggung dengan ketentuan:

a) Tertanggung tidak pernah mengajukan pembayaran / mengajukan polis,

b) Tertanggung tidak membatalkan polis.

2) Bagi hasil bagian tertanggung akan di hitung berdasarkan premi yang diterima oleh penanggung dikalikan dengan rate bagi hasil yang berlaku sampai akir pertanggungan polis.

b. Akad Wakalah

Pada akad ini terdapat pemisah antara pengelolaan dana pemegang saham dan dana peserta asuransi. Perusahaan memperoleh tabarru dari peserta dan berhak dipergunakan untuk seluruh kegiatan perusahaan. Untuk akuntansi dana pemegang saham dan dana peserta tidak harus dipisahkan.

\section{Klaim}

Klaim adalah hak peserta asuransi yang wajib diberikan oleh perusahaan asuransi sesuai dengan kesepakatan dalam akad, yang merupakan pengajuan hak yang dilaksanakan tertanggung kepada penanggung untuk memperoleh haknya berupa pertanggungan kerugian berdasarkan 
akad yang telah dibuat. Prosedur klaim, antara lain: pemberitahuan klaim (biasanya lisan dan diperkuat dengan bukti tertulis), bukti klaim kerugian, penyelidikan dan penyelesaian klaim. Jenis-jenis klaim, yaitu:

a) Klaim habis kontrak

Diajukan peserta karena perjanjian telah berakhir sampai batas yang telah disepakati. Dokumen yang diperlukan adalah formulir pengajuan klaim, polis asli, foto copy identitas diri yang masih berlaku dan buku asli pembayaran premi terakhir.

b) Klaim nilai tunai

Diakibatkan karena adanya kematian peserta dan yang mengajukan klaim adalah ahli waris yang tercantum pada polis/pihak lain yang diberikan kuasa. Adapun dokumen yang dibutuhkan adalah formulir pengajuan klaim, polis asli, foto copy ientitas diri yang berlaku, surat keterangan ari rumah sakit yang menjelaskan kenapa peserta meninggal, surat keterangan dari pamong praja dan surat keterangan dari Kepolisian Republik Indonesia jika musibah karena lalu lintas.

c) Klaim nilai tunai sebagian

Dilakukan peserta apabila jumlah polis mencapai 2 tahun dan aktif serta maksimal jumlah yang didapat 50\% dari saldo tabungan. Peserta tidak dikenakan beban sedikitpun karena itu termasuk bunga.

d) Klaim biaya perawatan

Pengantian kerugian peserta dengan alasan karena pengeluaran biaya oleh peserta dalam pengobatan/perawatan rumah sakit karena kecelakaan ataupun sakit. Dokumentasi yang diperlukan formulir pengajuan klaim, polis asli, foto copy identitas diri yang masih berlaku, resume dari rumah sakit dimana dirawat, laboratorium dan photo copy biaya pengobatan.

e) Klaim tahapan pendidikan

Klaim yang diajukan oleh peserta karena jatuh tempo dana pendidikan sebagaimana yang tercantum pada polis. Dokumentasinya formulir pengajuan klaim, polis asli, foto copy identitas diri yang masih berlaku, bukti asli pembayaran premi terakhir, surat jatuh tempo tahapan dari perusahaan (Sulistyowati, 2012). 
Tabel 2

Pembayaran Klaim Asuransi Syariah

\begin{tabular}{|c|l|}
\hline Kedudukan Peserta & \multicolumn{1}{|c|}{ Sumber Pembayaran Klaim } \\
\hline Tertimpa Musibah & 1. Tabungan peserta \\
& 2. Porsi bagi hasil investasi \\
& 3. Santunan dari rekening derma (tabarru') \\
\hline Habis Masa Kontrak & 1. Tabungan peserta \\
& 2. Porsi bagi hasil investasi \\
& 3. Santunan dari kelebihan Tabungan derma (tabarru') \\
& \\
& setelah digunakan untuk pembayaran klaim dan biaya \\
& operasional \\
\hline Mengundurkan Diri & 2. Pabungan peserta \\
&
\end{tabular}

\section{METODE PENELITIAN}

Penelitian ini memakai metode penelitian kualitatif, Teknik yang dipakai untuk menganalisis data yang terkumpul adalah metode deskriptif analitis dengan menggunakan pendekatan kualitatif.

\section{PEMBAHASAN}

Berdasarkan kajian teori, bisa dilihat bahwa mekanisme pengelolaan dana tabarru di perusahaan asuransi syariah dibagi menjadi dua rekening yaitu investasi/tabungan dan dana tabarru. Akad pada dana tabarru' merupakan akad yang dilakukan oleh dua orang atau lebih dengan tanpa mengharapkan imbalan dari pihak lainnya, serta dilandasi dengan sikap tolongmenolong antarsesama dan tidak untuk mencari keuntungan (nonprofit-oriented) (Karim, 2010).

Dana tabarru ini sepenuhnya milik peserta yang dihibahkan dengan tujuan untuk tolong menolong pada peserta lain jika tertimpa musibah. Asuransi syariah harus membawa unsur tolong-menolong, seperti yang terjadi pada awal sejarah adanya asuransi yang menjadikan prinsip tolong menolong sebagai unsur utama di dalamnya yang diberi konsep bernama takāful (Sulistyowati, 2012).

Dilihat pada Al Qur'an Surah al- Maidah (5) ayat 2, yang memuat perintah (amr) tolong menolong antar sesama manusia. Dalam bisnis asuransi, nilai ini tampak pada praktek kerelaan anggota perusahaan asuransi untuk menyisihkan dananya agar dipakai sebagai dana sosial (tabarru). Dan untuk dana sosial berubah rekening tabarru di perusahaan asuransi yang berfungsi untuk menolong anggota yang mengalami musibah (Ali, 2004). 
Dana tabarru' boleh digunakan untuk membantu siapa saja yang mendapat musibah. Karena dalam bisnis takāful yaitu melalui akad khusus, maka kemanfaatanya hanya terbatas pada peserta takâful saja. Dengan kata lain, kumpulan dana tabarru hanya dapat digunakan untuk kepentingan para peserta takäful yang mendapatkan musibah. Sekiranya dana tabarru tersebut digunakan untuk kepentingan lain, berarti ini melanggar syarat akad (Sula, 2004).

Namun, jika dilihat klaim yang berkaitan dengan dana tabarru, sesuai dengan Fatwa DSN No. 21 tahun 2001 tentang klaim asuransi syariah yang merupakan permintaan ahli waris/peserta atau pihak lain yang terlibat dalam perjanjian kepada perusahaan asuransi atau terjadinya kerugian sebagaimana yang diperjanjikan, atau aplikasi oleh peserta untuk memperoleh pertanggungan atas kerugian yang tersedia berdasarkan perjanjian (Sulistyowati, 2012).

Jika dicermati seperti ini maka tidak ada ketentuan jumlah dana tabarru yang dikeluarkan untuk peserta asuransi, dan tidak ada konsep yang mengatakan pengeluaran dana tabarru untuk peserta asuransi syariah ditentukan berdasarkan jumlah premi yang dibayarkan, kecuali untuk dana tabungan maka yang diperoleh sesuai dengan tabungannya dan bagi hasil yang diterima oleh peserta asuransi syariah. Bila demikian maka akan terlihat unsur ta'awun pada asuransi syariah yang dalam pertolongannya tidak membedakan peserta satu dengan yang lain, dan sebaik mungkin untuk pertolongan dana tabarru bisa dilihat berdasarkan kebutuhan dari peserta yang menerima musibah.

\section{PENUTUP}

Dana tabarru yang merupakan salah satu rekening di asuransi syariah dan menjadi pembeda dengan asuransi konvensional, ternyata mempengaruhi jumlah klaim asuransi yang diberikan kepada peserta asuransi syariah. Namun, untuk dana tabarru tidak ditentukan berdasarkan jumlah premi yang dibayarkan, kecuali untuk dana tabungan maka yang diperoleh sesuai dengan tabungannya dan bagi hasil yang diterima oleh peserta asuransi syariah. Hal ini sesuai dengan unsur ta’awun yang merupakan prinsip utama di asuransi syariah.

\section{DAFTAR PUSTAKA}

Ali, H. (2004). Asuransi dalam Perspektif Hukum Islam: Suatu Tinjauan Analisis Historis, Teoritis, \& Praktis. Jakarta: Kencana.

Amirun, A. (2019). Bisnis, Ekonomi, Asuransi, dan Keuangan Syariah. Jakarta: PT Grasindo. 
Amrin, A. (2006). Asuransi Syariah: Keberadaan dan Kelebihannya di Tengah Asuransi Konvensional. Jakarta: IKAPI.

Arif, N. R. (2012). Lembaga Keuangan Syariah. Bandung: Pustaka Setia.

Iqbal, M. (2006). Asuransi Umum Syariah dalam Praktik: Upaya Menghilangkan Gharar, Maisir, dan Riba. Jakarta: Gema Insani.

Karim, A. (2010). Bank Islam: Analisis Fikih dan Keuangan. Jakarta: Raja Grafindo Persada.

Kartiko, A. (2019). KONSEP BAGI HASIL DALAM PERSPEKTIF ISLAM. Indonesian Interdisciplinary Journal of Sharia Economics (IIJSE), 2(1), 1-19. https://doi.org/10.31538/iijse.v1i3.268

Latifah, N. A. (2012). Konsep dan Aplikasi Asuransi Syariah di Indonesia. Ahkam, Vol. 14, No.1, 104-105.

Nawawi, I. (2009). Ekonomi Kelembagaan Syariah: dalam Pusaran Perekonomian Global Sebuah Tuntutan dan Realitas. Surabaya: PMN.

S.Pradja, J. (2012). Lembaga Keuangan Syariah: Suatu Kajian Teoretis Praktis. Bandung: Pustaka Setia.

Saharuddin, D. (2014). Asuransi Syariah dalam Praktik: Studi Analisis terhadap Shariah Compliance. Esensi, Vol.4, No.3, 124.

Salamudin. (2014). Pengaruh Biaya Promosi terhadap Peningkatan Jumlah Peserta Asuransi: Studi di AJB Bumiputera 1912 Divisi Syariah. Al-Iqtishad, Vol.VI, No. 1, 122.

Sawitri, A. N. (2011). Analisis Investasi dalam Asuransi Syariah di Indonesia terhadap Portofolio Optimal. Media Ekonomi, Vol. 19, No.2, 31.

Sula, M. S. (2004). Asuransi Syariah (Life and General): Konsep dan Sistem Operasional. Jakarta: Gema Insani.

Sulistyowati. (2012). Dinamika dan Problematika Asuransi Syariah: Mekanisme Kerja Asuransi Syariah \& Prosedur Pembayaran Klaim. el-Qist, Vol.2, No.2, 230. 